\title{
Objectively measuring subjectively described traits: geographic variation in body shape and caudal coloration pattern within Vieja melanura (Teleostei: Cichlidae)
}

\author{
Caleb D. McMahan ${ }^{1}$, Justin Kutz², Christopher M. Murray ${ }^{3}$, Prosanta Chakrabarty ${ }^{2}$, \\ Aaron D. Geheber ${ }^{4}$ \& Diego Elías ${ }^{2}$ \\ 1. The Field Museum of Natural History, 1400 S. Lake Shore Drive, Chicago, IL 60605 USA; \\ cmcmahan@fieldmuseum.org \\ 2. LSU Museum of Natural Science (Ichthyology), Department of Biological Sciences, Louisiana State University, \\ Baton Rouge, LA 70803 USA; jkutz@live.com, prosanta@1su.edu, delias@1su.edu \\ 3. Department of Biological Sciences, Tennessee Tech University, Cookeville, TN 38505 USA; cmmurray@tntech.edu \\ 4. Department of Biology and Agriculture, University of Central Missouri, Warrensburg MO 64093 USA; \\ geheber@ucmo.edu
}

Received 06-VII-2016. Corrected 17-I-2017. Accepted 02-II-2017.

\begin{abstract}
Vieja melanura is a Neotropical cichlid occurring in the Petén-lake district systems of Guatemala, as well as the Río Grijalva-Usumacinta basin, and other systems in Southern México, Belize, and Guatemala. A caudal stripe, extending forward from the caudal peduncle, is characteristic of this species. This stripe is sloped downward in nearly all individuals of $V$. melanura, but the degree of the slope is highly variable throughout its range. The slope and shape of the stripe has previously been used in diagnosing and differentiating between species of Vieja. The purpose of this study was to use objective methods to investigate morphological variation in the caudal stripe and body shape throughout the range of $V$. melanura. We studied geometric morphometric analyses of body shape and empirical measurements of the slope of the caudal stripe in 215 specimens of $V$. melanura. We also used the mitochondrial cytochrome $b$ marker to study population level patterns within $V$. melanura. Results from our analyses showed significant geographic variation in body shape and patterns of coloration with little mitochondrial phylogeographic structure. These patterns likely correspond to differences in riverine habitats throughout the species' distribution. In conclusion, these results can be used to inform other studies of color and shape variation as it applies to taxonomy and systematics. Rev. Biol. Trop. 65 (2): 623-631. Epub 2017 June 01.
\end{abstract}

Key words: fish, morphometrics, cichlid, Central America, geography.

Vieja melanura is a species of Neotropical cichlid (subfamily Cichlinae; tribe Heroini) found in the Atlantic slope of Central America in the Petén lake district, Río Grijalva-Usumacinta system, and in neighboring drainages of México, Belize, and Guatemala (McMahan, Murray, Geheber, Boeckman, \& Piller, 2011). This species can be found in diverse habitats, ranging from lentic bodies of water such as lagoons and cenotes to more lotic systems (Miller, Minckley, \& Norris, 2006). Vieja melanura was formerly distinguished from closely related $V$. synspila (now a junior synonym of $V$. melanura) based on a supposed slope difference of a caudal stripe extending from the caudal peduncle to around $1 / 3$ body length. In assessing species limits of the two putative species, McMahan et al. (2011) noted, based on limited sampling, a relationship between the angle of the caudal stripe and standard length (SL) of specimens, with larger specimens possessing more angled caudal stripes. Therefore, the slope of the stripe was not diagnostic for either species. Furthermore, examination of the left and right sides of individual specimens indicated an asymmetry 
in the slope of the caudal stripe. This trend was found to be common in numerous individuals. However, in nearly all specimens previously examined, the caudal stripe begins at the middle of the posterior end of the caudal peduncle and extends to below the level of the lower lateral line, which equals a downward slope.

Morphological variation in fishes from different habitats is routinely reported in the literature (Mittelbach, Osenberg, Wainwright, 1999; Webster, Atton, Hart, \& Ward, 2011); yet this variation is rarely taken into account in taxonomic and morphological phylogenetic studies. In many studies few individuals are used to represent a species, and in fishes, as per convention, generally only the left side is described and used for data collection. In addition, this caudal stripe character is also commonly qualitatively described in morphological analyses and taxonomic descriptions (Hubbs, 1935). The purpose of this study was to investigate overall body shape and pattern variation of the caudal stripe across the range of $V$. melanura, and to re-assess the relationship between slope of the caudal stripe and size of specimens, throughout the distribution of this species. We objectively measured these traits using quantitative methods and tested for patterns of variation using morphological data in conjunction with genetic data.

\section{MATERIALS AND METHODS}

Body shape variation: Museum specimens from the University of Michigan Museum of Zoology (UMMZ) were selected from throughout the range of $V$. melanura. Material included specimens that varied by locality and size (Table 1). Specimens that would confound data such as curled, damaged, and badly faded individuals were not included in analyses. A total of 215 specimens were used. Additionally, data were collected without prior groupings by locality. These measures aided in eliminating outliers in the dataset. Locality data were recorded based on general river systems as in McMahan et al. (2011).

All individuals were assigned a unique identifier for reference, and standard length (SL) was recorded for each specimen using hand-held digital calipers. Photographs were then taken

TABLE 1

Specimens examined for geometric morphometric analyses of $V$. melanura

\begin{tabular}{lcllc} 
Catalog Number & N= & Country & Locality & SL \\
UMMZ 143937 & 24 & Guatemala & Lago Petén & $53.86-102.26$ \\
UMMZ 143940 & 27 & Guatemala & Lago Petén & $46.83-83.01$ \\
UMMZ 144035 & 7 & Guatemala & Río la Pasión & $57.1-70.86$ \\
UMMZ 144044 & 17 & Guatemala & Laguna Perdida & $62.98-97.87$ \\
UMMZ 144048 & 23 & Guatemala & Laguna Yalac & $84.56-142.75$ \\
UMMZ 144053 & 11 & Guatemala & Río la Pasión & $50.95-150.63$ \\
UMMZ 167692 & 1 & Belize & Río Belize & 85.23 \\
UMMZ 184637 & 1 & México & Río Grijalva & 120.54 \\
UMMZ 189959 & 23 & Guatemala & Río Chixoy & $73.82-151.85$ \\
UMMZ 189985 & 23 & Guatemala & Río Chixoy & $33.47-116.53$ \\
UMMZ 190149 & 1 & Belize & Río Belize & 47.25 \\
UMMZ 196435 & 20 & México & Río Usumacinta & $40.39-61.25$ \\
UMMZ 196488 & 2 & México & Laguna Bacalar & $73.57-124.84$ \\
UMMZ 196605 & 15 & México & Gulf of Campeche & $29.08-59.16$ \\
UMMZ 202885 & 13 & Belize & Río Belize & $38.95-42.84$ \\
UMMZ 210868 & 5 & México & Laguna Bacalar & $31.73-109.02$ \\
UMMZ 210943 & 2 & México & Río Usumacinta & $47.05-72.31$ \\
\hline
\end{tabular}

${ }^{1} \mathrm{UMMZ}=$ University of Michigan Museum of Zoology; SL = standard length in millimeters. 
of both the left and right side of each individual using a Canon EOS digital camera. Photographs were checked for clarity and retaken if landmark locations were indistinguishable or ambiguous. TPsUtil (Rohlf, 2009) was used to compile and append files, assign a group file, and group ID files. All photographs were rendered in TPsDig (Rohlf, 2008).

To quantify body shape, 13 homologous landmarks were placed using TPsDig (Fig. 1). These 13 landmarks have previously been used in geometric morphometric analyses of bodyshape variation in Neotropical cichlids including the studied species (McMahan et al., 2011). A W-matrix of partial warp scores for each landmark, as well as consensus landmarks, was obtained using TPsRegr (Rohlf, 2007). Partial warp scores were aligned for every individual as variables, adding the largest warp score (positive or negative) from each variable to make all values positive. The resulting file was input into Primer 6 (Clarke, 1993; Clarke \& Gorley, 2006) for subsequent analyses based on Murray, Piller, Merchant, Cooper and Easter (2013). Individuals were averaged over by locality (i.e. museum lot) to incorporate sampling location and size classes while allowing for concise visual interpretation. A non-parametric Multi-Dimensional
Scaling (MDS) with 50 iterations, based off of a Euclidean distance resemblance matrix, was used to assess body shape variation between specimen localities. This was further coupled with a CLUSTER analysis, which was utilized to determine percent similarity between localities and recovered statistical groupings.

Caudal stripe variation: Using the slope function in TPSDig, the angle of the caudal stripe on both the left and right sides of specimens was measured. A line was drawn through the lower lateral line and another through the center of the caudal stripe, with the two lines intersecting at the caudal peduncle (Fig. 1). Box plots were used to visually assess the overall degree of asymmetry between left and right sides of specimens. A t-test was used to assess significance in the data $(\mathrm{p} \leq 0.05)$. Because there were no obvious trends across specimens of consistently greater right or left side angles, the question became: do individuals consistently show asymmetry in stripe angle? Measured angles from the right side of all specimens were subtracted from their corresponding left-side angle measurements, producing an "asymmetry value" or angle difference for each individual. Absolute values were taken for angle differences to allow comparability

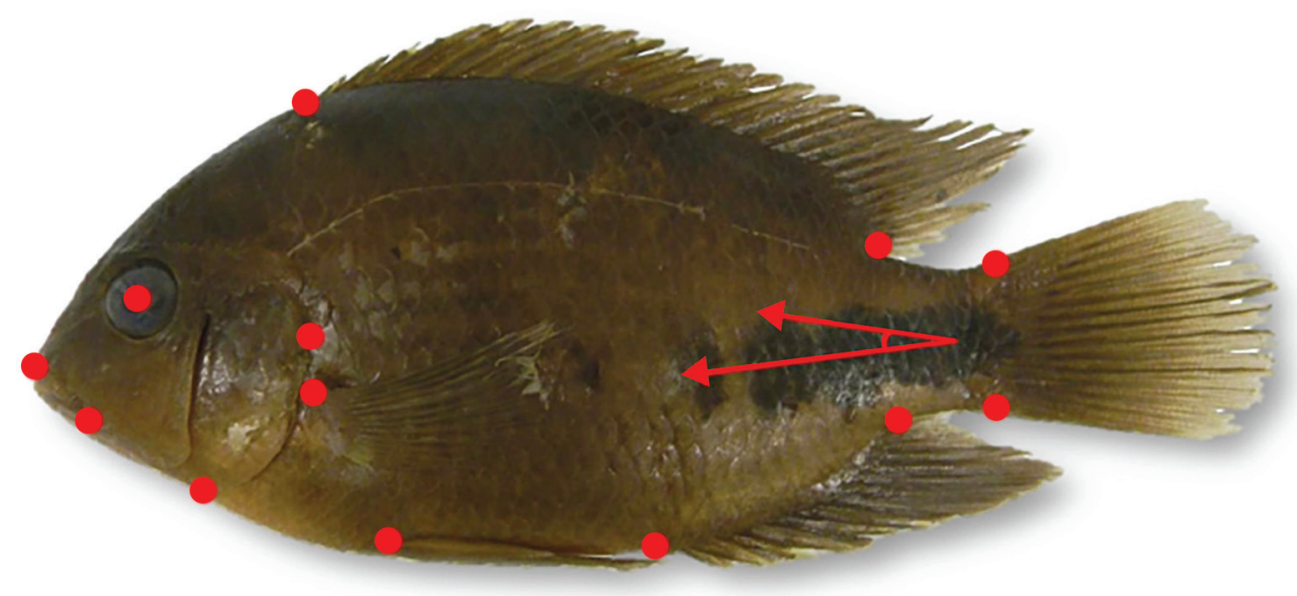

Fig. 1. Depiction of homologous landmarks and angle measurement protocol for caudal stripe of $V$. melanura. Top line through lower lateral line, bottom line through center of caudal stripe. 
against the absence of symmetry. These data failed the Shapiro-Wilk normality test, thus instead of running a one-sample t-test on angle differences, a nonparametric Wilcoxon signed rank test was used. The null hypothesis was $\mu=0$, because if no asymmetry exists then the difference between right and left side angles will be zero. However, this does assume complete accuracy in measurement of angles in the downward sloping stripe of specimens. Therefore, the Wilcoxon signed rank test was also performed with $\mu=1$, accounting for a onedegree error in measurement. While this may or may not reflect exact accuracy in these angle measurements, it does provide a more conservative assessment of asymmetry. Finally, a linear regression was then used to determine if a correlation exists between the standard length and caudal-stripe angle to assess ontogenetic shifts in this character.

Genetics: The mitochondrial cytochrome $b$ (cyt $b$ ) gene was studied to investigate general phylogeographic patterns for this species to assess if genetic patterns correspond to morphometric patterns. A sequence was available from GenBank for an individual from Río Belize, and material recently obtained by field collections from water bodies in the PeténLake district in Northern Guatemala, as well as portions of the Río Usumacinta basin including Río La Pasión, were sequenced as part of this study (Table 2). Primers and molecular methodology followed McMahan, Geheber and Piller (2010). Sequences were aligned by eye and a Parsimony analysis was implemented in PAUP* (Swofford, 2002) also following procedures of McMahan et al. (2010). GenBank accession numbers are presented in Table 2 . The sister species $V$. maculicauda was used as an outgroup taxon.

\section{RESULTS}

Body shape variation: The MDS plot (2D stress $=0.1$ ) revealed separation in body shape between two groups of specimens at $90 \%$ confidence (Fig. 2). These two groups depicted three lots of specimens from Belize grouping as quite distinct from specimens from México and Guatemala. The cluster analysis based on partial warp scores for overall body shape showed four separate clusters that correspond to geographic regions (Fig. 3). These results corroborated the results of the MDS plot, and also allowed more fine-scale resolution.

TABLE 2

GenBank accession numbers for cyt $b$ sequences

\begin{tabular}{lcllc} 
Voucher No. & Tissue No. & \multicolumn{1}{c}{ Locality } & GenBank No. \\
V. melanura & LSUMZ 16418 & LSUMZ-F 5865 & GT: Lago Yaxhá & KX874550 \\
& LSUMZ-F 5866 & GT: Lago Yaxhá & KX874551 \\
& LSUMZ 16387 & LSUMZ-F 5764 & GT: Lago Peten-Itzá & KX874557 \\
& LSUMZ-F 5765 & GT: Lago Peten-Itzá & KX874552 \\
& LSUMZ 16384 & LSUMZ-F 5981 & GT: Laguna Macanche & KX874559 \\
& LSUMZ 16354 & LSUMZ-F 5949 & GT: Lago Yaxhá & KX874556 \\
& LSUMZ-F 5950 & GT: Lago Yaxhá & KX874554 \\
LSUMZ 16464 & LSUMZ-F 5995 & GT: Río La Pasion & KX874555 \\
& LSUMZ-F 6012 & GT: Río La Pasion & KX874558 \\
STRI 8020 & - & GT: Río Usumacinta & AY843418 \\
STRI 7975 & - & GT: Río Usumacinta & AY843413 \\
STRI 8070 & - & GT: Río Belize & AY843420 \\
\hline
\end{tabular}

${ }^{1}$ LSUMZ $=$ LSU Museum of Natural Science; STRI=Smithsonian Tropical Research Institute ${ }^{2} \mathrm{GT}=$ Guatemala, $\mathrm{HN}=$ Honduras. 

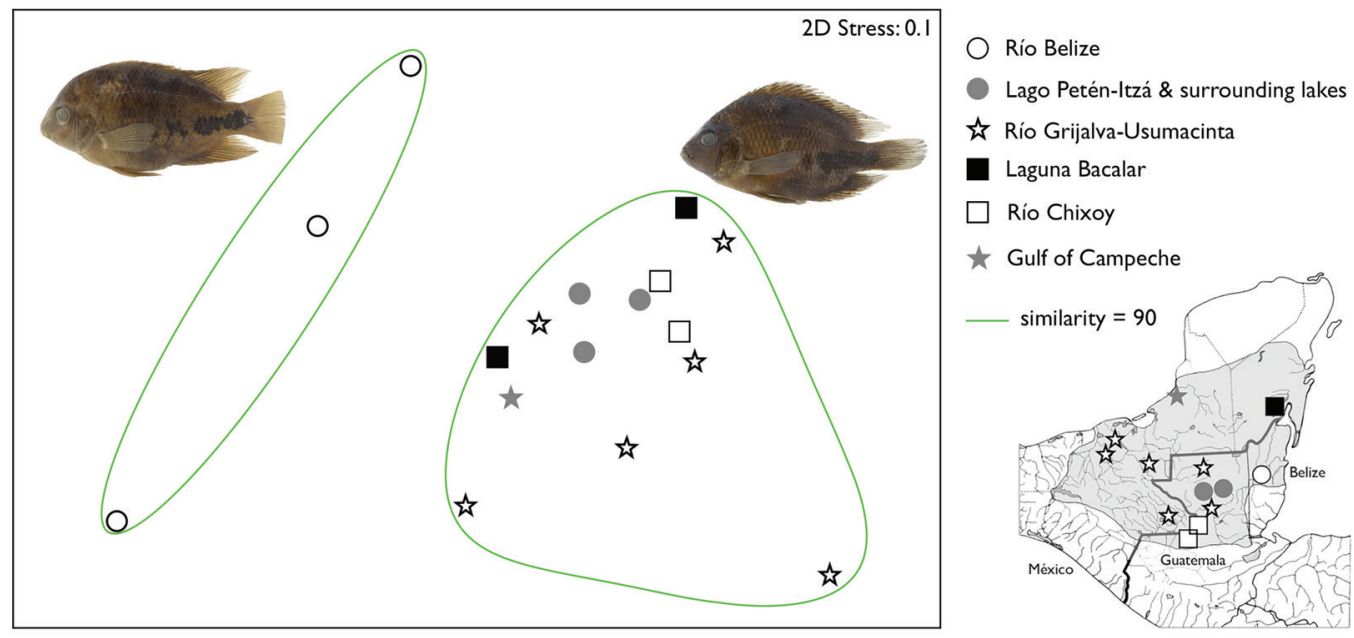

Fig. 2. Multi-dimensional scaling (MDS) of geometric morphometric data distinguished and averaged over by museum lot (collecting event), with each point representing a lot. Shaded region on map illustrates distribution of $V$. melanura and points represent collection localities; some localities represent multiple museum lots.

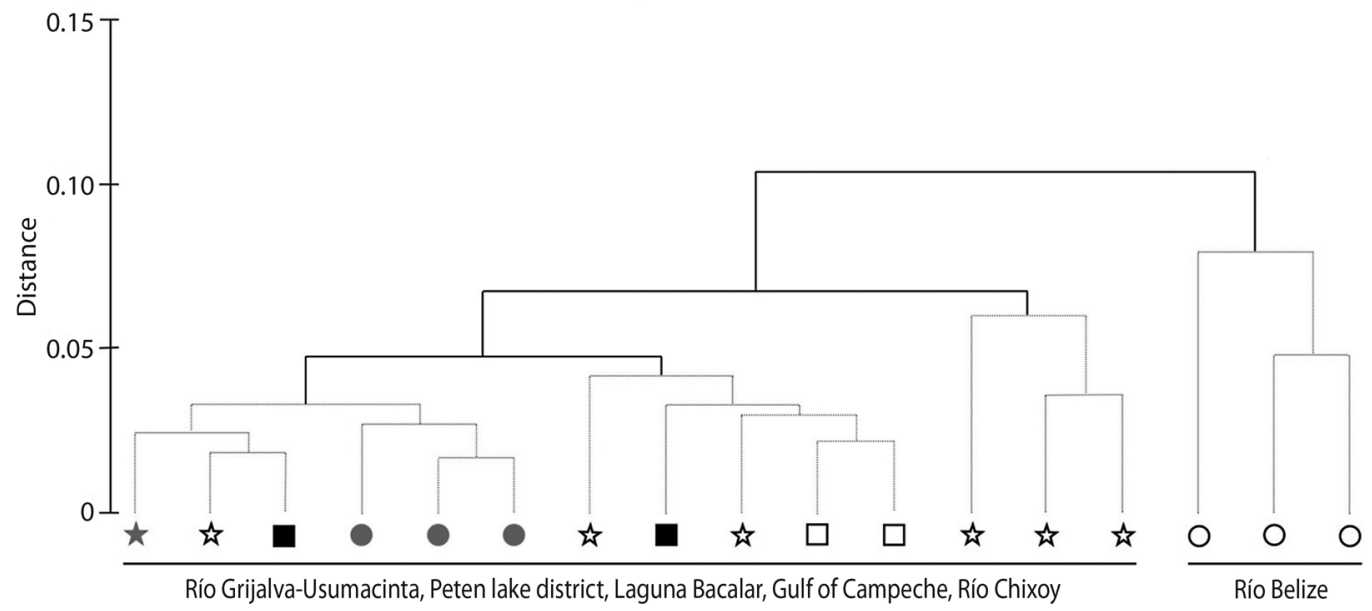

Fig. 3. Results of a complete linkage (by museum lot/collecting event) cluster analysis of geometric morphometric data. Locality symbols follow Fig. 2. Solid lines indicate significant differences between clusters.

Two clusters were recovered from México, with a difference of $5 \%$. The cluster of specimens from Guatemala was $7 \%$ different from those collected in México. Finally, the Belize cluster was $10.5 \%$ different from the specimens from México and Guatemala.

Caudal stripe variation: Box plots used to visualize variation in the characteristic downward sloping caudal stripe of this species (Fig. 4) showed a high degree of overlap between the angle of the caudal stripe on the left and right side of individuals. Furthermore, a t-test showed no significant differences between left and right sides of specimens $(\mathrm{p}=$ 0.588 ). No asymmetry was found such that one side was always or frequently at a lower/higher angle than the other. However, the spread 


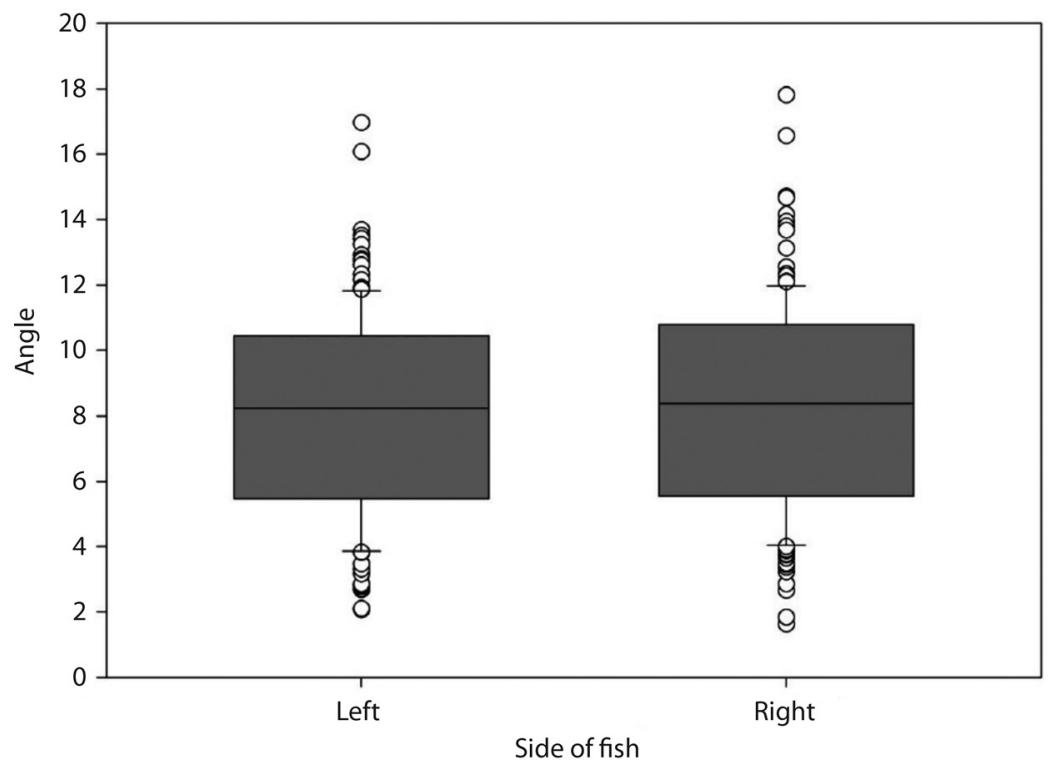

Fig. 4. Box plot to visualize caudal stripe asymmetry across specimens of $V$. melanura.

of points above and below boxes on each side (Fig. 4) indicated high levels of variation across individuals in the angle of the stripe for both left and right sides.

To investigate this result further, we used Wilcoxon signed rank tests to assess if asymmetry exists in the downward sloping caudal stripe of this species across its geographic distribution. Under an assumption of $\mu=0, \mathrm{~V}=$ 11175 we obtained $p=<2$.2e-16. When attempting to be more conservative and assuming some degree of inaccuracy in angle measurements $(\mu=1)$, we similarly obtained $\mathrm{V}=9201$ and $\mathrm{p}=7.54 \mathrm{e}-12$. These results revealed consistent asymmetry in slope of the caudal stripe across individuals of $V$. melanura.

Linear regressions (Fig. 5) showed a significant correlation between caudal stripe angle and size of specimens examined. The downward sloping angle of the caudal stripe increased with increasing size of specimens, and presumably age. For the right side, $\mathrm{r}^{2}=0.1699$ $(\mathrm{df}=(1,147), \mathrm{F}=30.08, \mathrm{p}<0.0001)$, and for the left side of specimens, $\mathrm{r}^{2}=0.11(\mathrm{df}=(1,147)$, $\mathrm{F}=18.21, \mathrm{p}<0.0001)$.
Genetics: Sequences from 14 individuals were included in the cyt $b$ alignment. The final alignment was 1137 base pairs with eight parsimony informative sites. Overall genetic variation within this species was minimal; however, three shallow clades were recovered (Fig. 6). These clades included the water bodies of the Petén-lake district in Northern Guatemala, the Río Usumacinta drainage (including Río La Pasión), and the Río Belize system. On average, clades were $0.4-0.7 \%$ divergent from each other. While divergence is minimal this shallow genetic differentiation was congruent with the MDS clusters based on body shape (Figs. 2 and 6). The outgroup taxon $V$. maculicauda was $1.8-2.1 \%$ divergent from specimens of $V$. melanura.

\section{DISCUSSION}

Vieja melanura has a notable distribution; it is one of a few Central American species that occurs in drainages on both Atlantic slopes (Gulf of México and Caribbean) of the Yucatán Peninsula (Matamoros, McMahan, 


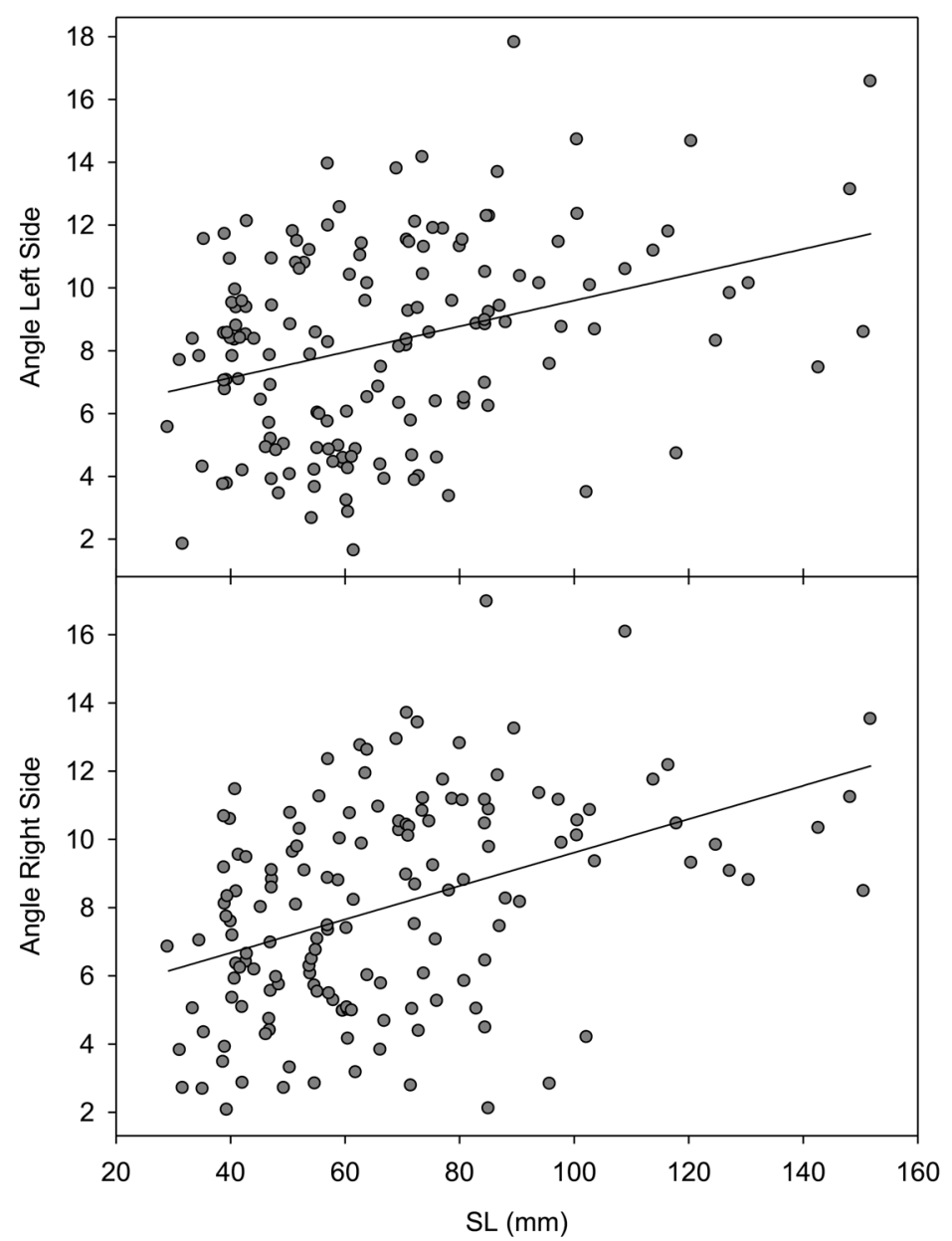

Fig. 5. Scatterplots showing significant correlation between angle of caudal stripe of left (top graph) and right (bottom graph) sides and standard length (SL) in V. melanura. Overall trends show increase in caudal-stripe angle as SL increases.

Chakrabarty, Albert, \& Schaefer, 2015). The main pattern observed regarding body shape variation in $V$. melanura indicates that specimens from drainages in Belize are significantly distinct from those in Guatemala and México. We hypothesize these morphological shape differences are likely due to differences in habitat variables such as river flow, which has been documented in other groups of fishes (Haas, Blum, \& Heins, 2010). The freshwater systems in Belize where this species occurs are smaller and possess more flow than the more expansive and slower flowing (e.g. "bayou") stretches of the Río Usumacinta where this species is also found (Greenfield \& Thomerson, 1997; Esselman, Freeman, \& Pringle, 2006; Miller et al., 2006), as well as lakes such as those in the Lago Petén district in Northern Guatemala (Kihn-Pineda, Cano, \& Morales, 2006). These body shape differences are remarkably congruent with the observed, but shallow, population-level differentiation within this species. This pattern of low intraspecific genetic divergence is also observed in other Central American cichlids (López-Fernández, Winemiller, \& Honeycut, 2010; McMahan et al., 2010). 


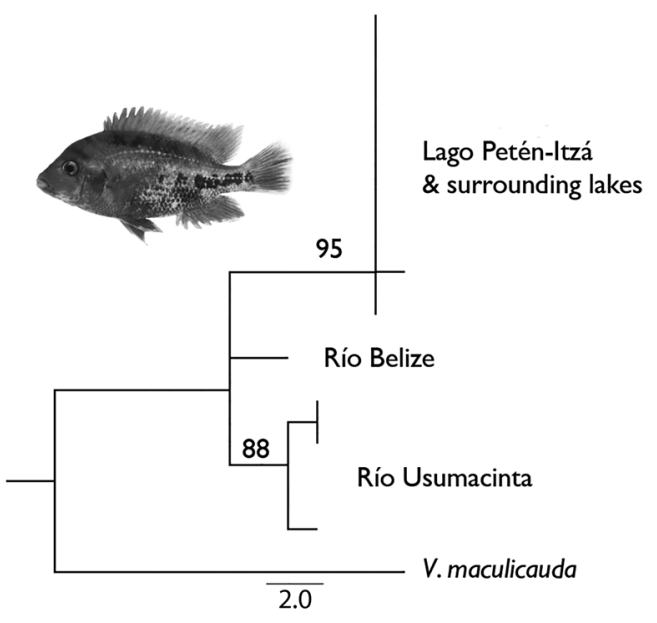

Fig. 6. Parsimony phylogeny of $V$. melanura based on cyt $b$ sequence data. Numbers on clades indicate bootstrap values.

Additional material of $V$. melanura from rivers in the Caribbean slope would aid in corroborating this hypothesis.

We found that the caudal stripe of $V$. melanura is highly variable throughout the relatively widespread distribution of this species, corroborating the findings of McMahan et al. (2011). While we expected significant asymmetry in the angle of the caudal stripe between the left and right sides of individuals, this was not the overall pattern. However, the comparison of left and right side caudal-stripe angles shows that the largest angle for the right side is still greater than the largest angle for the left side. The same pattern is true for the smallest angles. This observation indicates that at least some amount of asymmetry exists for this character throughout the distribution of this species.

Finally, the results from this study also have implications for taxonomic and morphological studies, as characteristics of the caudal stripe were previously used to diagnose multiple species within V. melanura (Hubbs, 1935). This study illustrates the importance of careful attention to variation (including leftright asymmetry) in investigating differences between morphologically variable fishes, and the influence of biotic and abiotic interactions on these traits. It is routine in specimen-based ichthyological studies to only record data on one side of fish specimens (for consistency). Based on the results of this study we suggest that it may be important to consider patterns on the opposite side for some traits.

\section{ACKNOWLEDGMENTS}

We wish to thank Wilfredo Matamoros for assistance with data analyses. An NSF Research Experience for Undergraduates award from Louisiana State University's Office of Strategic Initiatives supported Justin Kutz. Daniel Le (FMNH) kindly assisted with photos for figure production. We thank Doug Nelson of the University of Michigan Museum of Zoology for assistance with specimen loans. This work was supported by NSF DEB 0916695 and DEB 1354149 to PC and NSF DEB 1311408 to CDM. We thank CONAP and CECON for permits to work in Guatemala.

\section{RESUMEN}

Midiendo objetivamente caracteres subjetivos: variación geográfica en la forma del cuerpo y patrones de coloración caudal de la especie Vieja melanura (Teleostei: Cichlidae). Vieja melanura es un cíclido neotropical (subfamilia Cichlinae; tribu Heroini) que se encuentra en los lagos del distrito de Péten en Guatemala, así como en la Cuenca del Río Grijalva-Usumacinta, y otros sistemas acuáticos en el sur de México, Belice y Guatemala. Una banda oscura que se extiende desde el pedúnculo caudal hacia la porción anterior del mismo es característica de esta especie. Esta banda está inclinada hacia abajo en casi todos los individuos de $V$. melanura, pero el grado de inclinación es altamente variable a lo largo del rango de distribución de la especie. La pendiente y forma de la banda se ha utilizado anteriormente como carácter diagnóstico entre especies del género Vieja. El propósito de este estudio fue investigar la variación morfológica en la forma del cuerpo y en los patrones de coloración de la banda caudal a lo largo del rango de distribución de $V$. melanura utilizando métodos objetivos. Analizamos la forma del cuerpo utilizando morfometría geométrica, medimos empíricamente la pendiente de la banda caudal en 215 especimenes. Finalmente evaluamos si existen patrones de estructura genética a nivel de poblaciones utilizando el marcador mitocondrial Citocromo b a lo largo del rango de distribución de $V$. melanura. Nuestros resultados muestran que la forma del cuerpo y los patrones de coloración 
de la banda caudal varian significantemente a lo largo del rango de distribución de $V$. melanura pero presenta poca estructura filogeografica. Estos patrones pueden ser explicados plausiblemente por diferencias en los hábitats riverinos presentes a lo largo del rango de distribución de la especie. En conclusión estos resultados se pueden utilizar como referencia en otros trabajos de taxonomía y sistemática que investiguen variación en la forma del cuerpo y patrones de coloracion en peces neotropicales.

Palabras clave: pez, morfometría, cíclido, América Central, geografía.

\section{REFERENCES}

Clarke, K. R. (1993). Non-parametric multivariate analyses of changes in community structure. Australian Journal of Ecology, 18, 117-143.

Clarke, K. R., \& Gorley, R. N. (2006). PRIMER v6: User Manual/Tutorial. Plymouth, England: PRIMER-E.

Esselman, P. C., Freeman, M. C., \& Pringle, C. M. (2006). Fish-assemblage variation between geologically defined regions and across a longitudinal gradient in the Monkey River Basin, Belize. Journal of the North American Benthological Society, 25(1), 142-156.

Greenfield, D. W., \& Thomerson, J. E. (1997). Fishes of the Continental Waters of Belize. Gainesville, Florida: University Press of Florida.

Haas, T. C., Blum, M. J., \& Heins, D. C. (2010). Morphological responses of a stream fish to water impoundment. Biology Letters, 6(6), 803-806.

Hubbs, C. L. (1935). Fresh-water fishes collected in British Honduras and Guatemala. Miscellaneous Publications, Museum of Zoology, University of Michigan, $28,1-22$.

Kihn-Peneda, P. H., Cano, E. B., \& Morales, A. (2006). Peces de las aguas interiores de Guatemala. In E. B. Cano (Ed.), Biodiversidad de Guatemala (pp. 457-486). Guatemala: Universidad del Valle de Guatemala.

López-Fernández, H., Winemiller, K. O., \& Honeycut, R. L. (2010). Multilocus phylogeney and rapid radiations in Neotropical cichlid fishes (Perciformes:
Cichlidae: Cichlinae). Molecular Phylogenetics and Evolution, 55(3), 1070-1086.

Matamoros, W. A., McMahan, C. D., Chakrabarty, P., Albert, J. S., \& Schaefer, J. F. (2015). Derivation of the freshwater fish fauna of Central America revisited: Myers's hypothesis in the twenty-first century. Cladistics, 31(2), 177-188.

McMahan, C. D., Murray, C. M., Geheber, A. D., Boeckman, C. D., \& Piller, K. R. (2011). Paraneetroplus synspilus is a junior synonym of Paraneetroplus melanurus (Teleostei: Cichlidae). Zootaxa, 2833, 1-14.

McMahan, C. D., Geheber, A. D., \& Piller, K. R. (2010). Molecular systematics of the enigmatic Middle American genus Vieja (Teleostei: Cichlidae). Molecular Phylogenetics and Evolution, 57(3), 1293-1300.

Murray, C. M., Piller, K. R., Merchant, M., Cooper, A., \& Easter, M. E. (2013). Salinity and egg shape variation: a geometric morphometric analysis. Journal of Herpetology, 47(1): 15-23.

Miller, R. R., Minckley, W. L., \& Norris, S. M. (2006). Freshwater Fishes of Mexico. Chicago, USA: University of Chicago Press.

Mittleback, G. C., Osenberg, C. W., \& Wainwright, P. C. (1999). Variation in feeding morphology between pumpkinseed populations: Phenotypic plasticity or evolution? Evolutionary Ecology Research, $1,111-128$.

Rohlf, J. F. (2008). TpsDig. Ecology and Evolution. New York, USA: SUNY at Stony Brook.

Rohlf, J. F. (2007). TpsRegr, thin plate spline regression, version 1.35. New York, USA: SUNY at Stony Brook.

Rohlf, J. F. (2009). Tps Utility Program. Ecology and Evolution. New York, USA: SUNY at Stony Brook.

Swofford, D. L. (2002). PAUP*, Phylogenetic Analysis Using Parsimony (*and other methods), version 4.0. Sunderland, MA.: Sinauer Associates.

Webster, M. M., Atton, N., Hart, P. J. B., \& Ward, A. J. W. (2011). Habitat-specific morphological variation among Threespine Sticklebacks (Gasterosteus aculeatus) within a drainage basin. PLoS ONE, 6(6), e21060. 
